\title{
Demography and Clinical Features of Chalazion Among Patients Seen at a Multi-Tier Eye Care Network in India: An Electronic Medical Records Driven Big Data Analysis Report
}

This article was published in the following Dove Press journal:

Clinical Ophthalmology

\author{
Anthony Vipin Das (iD) \\ Tarjani Vivek Dave ${ }^{2}$ \\ 'Department of eyeSmart EMR \& AEye, \\ L V Prasad Eye Institute, Hyderabad, \\ Telangana, India; ${ }^{2}$ Ophthalmic Plastic \\ Surgery Service, L V Prasad Eye Institute, \\ Hyderabad, Telangana, India
}

Purpose: To describe the prevalence, demographics and clinical presentations of chalazion in patients presenting to a multi-tier ophthalmology network in India.

Materials and Methods: This was a cross-sectional observational multi-centric hospitalbased study of 1,982,058 new patients presenting between 2010 and 2019. Patients with both symptoms and signs of chalazion were considered as subjects. The data were retrieved using an electronic medical record system.

Results: Overall, 11,270 (0.57\%) new patients were diagnosed with chalazion. Of these, $1,085(10 \%)$ patients had recurrent chalazia. The prevalence rates were $0.95 \%$ in children and $0.51 \%$ in adults. Males accounted for $51 \%$ of the cases, and $79 \%$ had unilateral affliction. The commonest age group affected was the third decade of life (31\%). Of the 13,691 affected eyes with chalazion, 39\% were located in the upper eyelid, $6 \%$ were lateral in position and $3 \%$ have multiple swellings at presentation. Conservative treatment was the preferred treatment modality in $85 \%$. Incision and curettage were performed in $15 \%$ eyes and intralesional steroid in $0.55 \%$ eyes. Of the $15 \%$ patients that were advised surgery, $9 \%$ underwent the procedure with a conversion rate of $58 \%$.

Conclusion: Only a miniscule percentage of patients seeking eye care in India are affected by chalazion. It is slightly more common in males and is usually unilateral and largely affects the upper eyelids. It is recurrent in a tenth of the cases. Conservative management is the preferred modality.

Keywords: chalazion, epidemiology, big data, electronic medical records
Correspondence: Tarjani Vivek Dave Ophthalmic Plastic Surgery Service, L V Prasad Eye Institute, Hyderabad 500034, Telangana, India

Tel +9l-7680849900

Email tvdeye@gmail.com

\section{Introduction}

Chalazion is one of the commonest type of eyelid lesions seen in the ophthalmology clinic. ${ }^{1}$ Pathologically, chalazion is a chronic, lipogranulomatous inflammatory lesion caused by the blockage of the meibomian glands. They usually are asymptomatic, may have a cosmetic blemish or may rarely cause local infections like conjunctivitis or cellulitis. ${ }^{2}$ Large chalazia can occasionally cause visual loss by obstructing the pupil. ${ }^{3}$ Conservative treatment measures include the use of eyelid hygiene, hot compresses, and antibiotic and/or steroid drops. In case of failure of the above measures, intralesional corticosteroid injections or incision and curettage (I\&C) to excise the lesion can be resorted to. 
Though abundant literature exists on comparison of management modalities in chalazion, large data on the demographics and epidemiology of chalazion is scarce. The largest data set available in the literature describing the demography and epidemiology in chalazion included 97 patients. ${ }^{4}$ This represents a very miniscule number with respect to the general footfall of chalazion patients over the world. In the current age of data informatics, it is possible to extract large volumes of data from electronic medical record systems which can assist further understanding of disease demography and management. In the current communication, we report the demography, epidemiology and clinical patterns of patients with chalazia presenting to our multi-tier eye care network, a big data analysis retrieved from an indigenous developed electronic medical record system.

\section{Materials and Methods Study Design}

This is a cross-sectional hospital-based observational study. Patients newly diagnosed with chalazion presenting between August 2010 and December 2019 to our eye care network located in 200 different geographical locations spread across four states of India were included. The patient or their parents or guardians filled a standard consent form for electronic data privacy at the time of registration. None of the identifiable parameters of the patient were used for analysis of the data. The study adhered to the Declaration of Helsinki and was approved by the Institutional Ethics Committee (Ethics approval no. LEC-BHR-R-05-20-442). Each patient underwent a comprehensive ophthalmic examination and the clinical data was entered into a browserbased electronic medical records system (eyeSmart EMR). ${ }^{5}$

\section{Data Retrieval and Processing}

The data of 1,982,058 patients were retrieved from the electronic medical record database and segregated into a single excel sheet based on the departments. The 11,270 eligible chalazion patients in this group were segregated for analysis. A total of 13,691 eyes of 11,270 patients were included for the study. The columns with data on demographics, clinical presentation and ocular diagnosis were exported for analysis. The excel sheet with the required data was then used for analysis using the appropriate statistical software. The geographic categorization of the districts of India was performed in accordance to the National Sample Survey Organization (NSSO) which defines "rural" as an area with a population density of up to 400 per square kilometer. ${ }^{6}$ The Constitution (seventy-fourth Amendment) Act, 1992 defines a metropolitan area in India as an area having a population of one million or more, comprised in one or more districts and consisting of two or more municipalities or panchayats or other contiguous areas, specified by the Governor by public notification to be a metropolitan area. The remaining districts were classified as urban. ${ }^{7}$ The general principle of treatment followed was to offer conservative treatment if the chalazion was $10 \mathrm{~mm}$ or less in size, marginal in location, in close association with the punctum or associated with secondary infection. However, if a patient was keen on incision and curettage in the first sitting itself, that was the treatment provided. Conservative treatment consisted of warm compress, tetracycline eye ointment, and eyelid massage.

\section{Results}

\section{Incidence and Prevalence}

Of the 1,982,058 new patients who presented for an eye examination between August 16, 2010 and December 312019 , in the multi-tier hospital network, 11,270 new patients were diagnosed with chalazion translating into a prevalence rate of $0.57 \%$ (95\% CI $0.569-0.571)$ or 5,686/million population. The number of patients with recurrent symptoms was 1,085 patients at a recurrence rate of $9.63 \%(95 \%$ CI 9.1-10.2\%).

\section{Age}

The mean age of the patients with chalazion was 27.48 \pm 15.64 years while the median age was 25 (IQR:17-36) years. Around $23.57 \%$ of the patients were children and 76.43 adults. The distribution of chalazion in each agedecade is presented in Figure 1. The overall prevalence of chalazion was $0.95 \%(2656 / 280,034)$ in children and $0.51 \%(8614 / 1,702,024)$ in adults. The prevalence of chalazion increased steadily from the first decade (12.7\%) with peaking in the third decade of life (30.84\%) followed by a decline from the fourth decade (15.1\%).

\section{Gender}

There were 5,738 (50.91\%) male and 5,532 (49.09\%) female patients with chalazion. The overall prevalence of chalazion was slightly lower in males $(0.54 \%$; 5,738 / $1,051,339)$ compared to females $(0.59 \% ; 5,532 / 930,719)$ $(p=0.00001$ ). (Figure 2) Among the patients with chalazion, the mean and median age were $30.89 \pm 16.47$ and 29 (IQR: $20-41$ ) years for males and $23.94 \pm 13.87$ and 21 
35

30.84

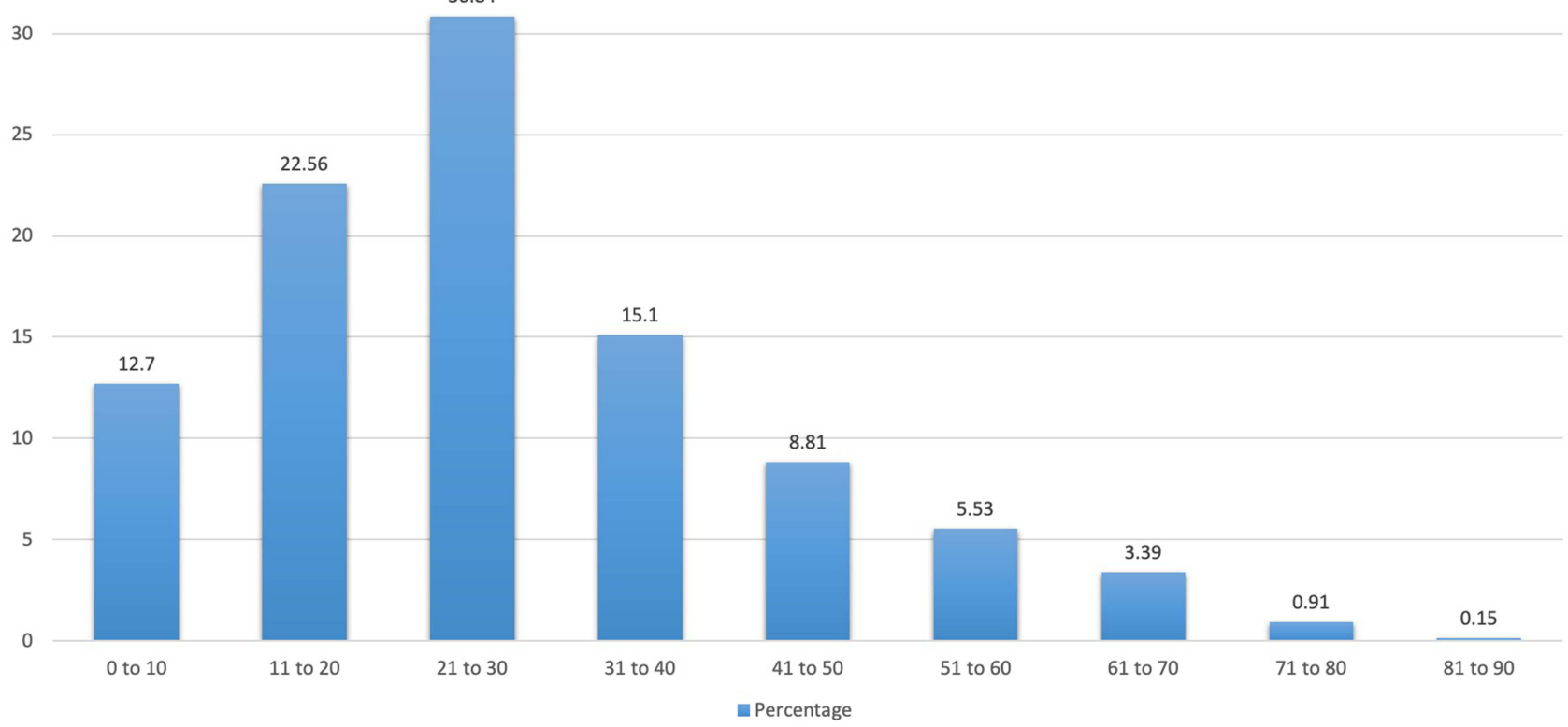

Figure I Decade-wise distribution of chalazion cases.

A

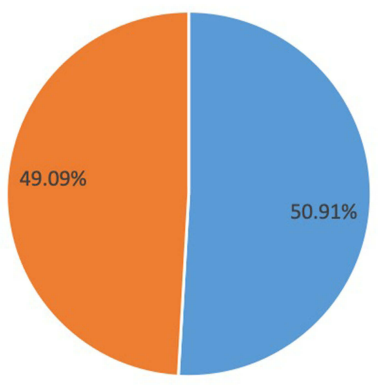

- Male a Female

D

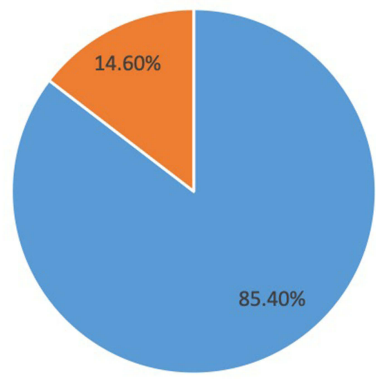

- Middle to High Income = Low Income
B

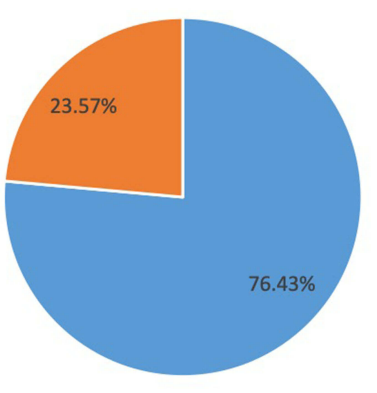

- Adult $=$ Paediatric

E

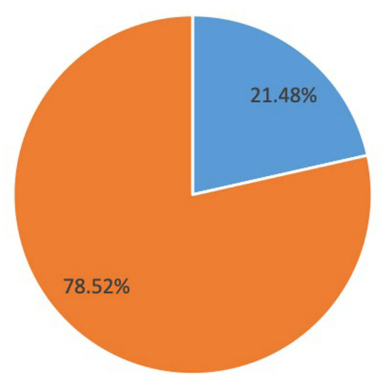

- Bilateral = Unilateral
C

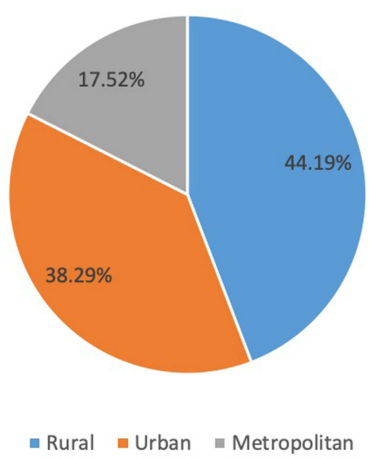

F

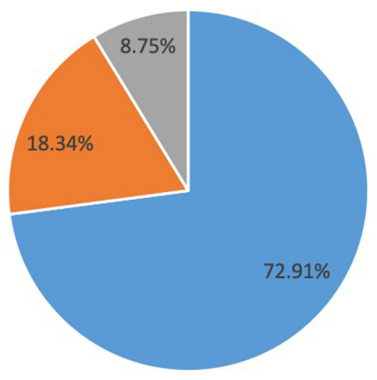

" Conservative $=$ No Intervention $₫$ Surgical

Figure 2 Graph showing demographics of cases with chalazion. (A) gender distribution, (B) age distribution, (C) geographic distribution, (D) socio-economic status, (E) laterality and $(\mathbf{F})$ management. 
(IQR: 15-29) years for females, respectively. The overall mode was 26 years in males and 21 years in females.

\section{Urban-Rural-Metropolitan Distribution}

There were 4,980 (44.19\%) patients with chalazion from rural districts, 4,315 (38.29\%) from urban districts and $1,975(17.52 \%)$ from metropolitan regions. The overall prevalence of chalazion was significantly higher $(p<0.0001)$ in metropolitan communities $(1.06 \% ; 1,975 / 187,034)$ as compared to the rural $(0.56 \% ; 4,980 / 894,897)$ and urban community $(0.48 \% ; 4,315 / 900,127)$ (Figure 2$)$.

\section{Socio-Economic Status}

There were 1,645 (14.6\%) patients with chalazion from the lower socio-economic class, 8,936 (79.29\%) from the lower middle class, 492 (4.37\%) from the upper middle class and 197 (1.75\%) from the upper class (Figure 2). The overall prevalence of chalazion was significantly higher $(p<0.0001)$ in the higher socio-economic strata $(0.66 \%$; $9,625 / 1,452,463)$ as compared to lower socio-economic strata $(0.31 \% ; 1645 / 529,595)$.

\section{Occupation}

Of the 11,270 patients with chalazion, 4,927 (43.72\%) were students, 2,834 (25.15\%) were professionals, 1,401 $(12.43 \%)$ were homemakers, 470 (4.17\%) were agricultural workers; $372(3.3 \%)$ were manual laborers, 133 $(1.18 \%)$ were currently not employed (retired or unemployed) and in the remaining 1,133 (10.05\%) the occupational category was not available/applicable. The overall prevalence of chalazion in students $(1.48 \%, 4,927 /$ $333,482)$ and professionals $(0.81 \%, 2,834 / 351,700)$ were significantly higher $(p<0.00001)$ in comparison to other professions.

\section{Presenting Complaints and Laterality}

Among the 11,270 patients, a tenth of the cohort complained of recurrent swelling in 1,085 (9.63\%) patients and a small percentage had multiple swellings at presentation in 342 (3.03\%) patients. The average duration of symptoms before presentation was $3.49 \pm 4.85$ months (median, 3 months, range 1-8 months). The chalazion was more commonly unilateral with similar distribution affecting the left eye in $4,559(40.45 \%)$ patients and right eye in 4,290 (38.07\%) patients. It was bilateral in 2,421 (21.48\%) patients.

\section{Anatomical Location and Position}

Chalazion was present in 13,691 eyes of 11,270 patients. The chalazion involved the upper eyelid in 5,366 (39.19\%) eyes, lower eyelid in 4,148 (30.3\%) eyes and both the eyelids in $1,102(8.05 \%)$ eyes. The anatomical position was not available in $3,075(22.46 \%)$ eyes. The lesion was lateral in 796 (5.81\%) eyes, medial in 654 (4.78\%) and central in $142(1.04 \%)$ eyes where the data was available.

\section{Misdiagnosis in Chalazion}

Of the 11,270 patients with chalazion, 20 were eventually diagnosed to not have chalazion, amounting to $0.18 \%$ incidence of false positives. Of these $6(0.05 \%)$ were diagnosed with Sebaceous Gland Carcinoma on subsequent follow ups and were treated with eyelid excision biopsy and reconstruction. Another 14 (0.12\%) had recurrent symptoms and were subjected to excision of the cyst with histologic examination revealing a intratarsal keratinous cyst in $6(0.05 \%)$ and eight others were diagnosed to have an epidermoid cyst.

\section{Management and Indications for Surgery}

A total of 2,067 (18.34\%) patients opted for no treatment. The chalazion was managed conservatively with warm compresses, tetracycline eye ointment and eyelid massage in $8,217(72.91 \%)$ patients. Incision and curettage was indicated and advised in 1,652 (14.66\%) patients and intralesional steroid Injection was advised in $62(0.55 \%)$ patients. Overall, 1,714 (15.21\%) patients were advised to have an intervention and it was performed in $986(8.75 \%)$ with a surgical conversion rate of $57.53 \%$ (986/1714) (Figure 2).

\section{Seasonal Variation}

The presentation of patients did not follow any seasonal pattern during the year which was steady from the month of January to December with an average of $8.33 \%$ per month. The percentage of the lowest cases being $7.29 \%$ in April to the highest being $9.36 \%$ in December. The month wise percentage of chalazion cases compared to the footfalls of the total patients presenting to the eye care centers is described in Figure 3.

\section{Discussion}

The current paper describes the demography of patients with a clinical diagnosis of chalazion at various centers of 
$0.90 \%$

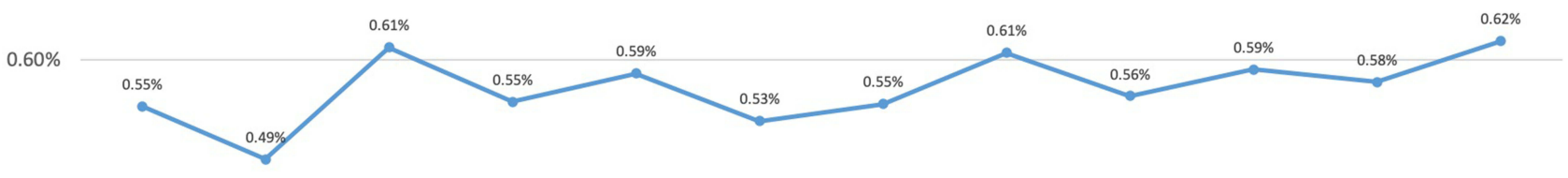

$0.30 \%$

$0.00 \%$

$$
\text { Jan }
$$

Feb

Mar

Apr

May

Jun

Jul

Aug

Sep

Oct

Dec

Figure 3 Seasonal prevalence of cases with chalazion.

an eye care center network in southern India over a 10 year time period. This was achieved via an indigenous electronic medical record system using big data analytics. Among the overall patient footfall, the study reports a chalazion prevalence rate of $0.57 \%$ with a mean presentation in the second decade of life. Though there was no gender predilection, significantly higher number of cases were from urban or metropolitan communities as compared to rural communities. Socio-economically, the middle-class population had a higher prevalence.

This is the largest series till date describing the demography and presentations of chalazion. The largest previous series was reported from Nigeria which included 97 cases from among 13,605 new cases examined over a 10-year period. They reported a prevalence of $0.7 \%$ which was statistically higher than that in the current study $(p=0.04)$. The mean age in their study was $25.3 \pm 10.5$ years which was comparable to the current study ( $p=0.17$ ). The upper eyelid in their study was involved more commonly, seen in $65.3 \%$ while in the current study it was seen in $39 \%(p<0.0001)$. In the Nigerian study, $74.6 \%$ of patients were treated with surgery which was by incision and curettage. In the current study, incision and curettage was performed in 986 (8.75\%) $(p<0.0001)$. Conservative management was offered in $15.25 \%$ and $72.91 \%$ respectively $(p=0.003)$.
The previous largest demographic study on chalazion from India reported 75 cases over a 2-year period. ${ }^{8}$ In that study, prevalence chalazion was found to be $0.24 \%$ among the patients visiting the eye outpatient department. Out of 75 patients, $24(32 \%)$ were male and $51(68 \%)$ were female. Among 24 males $16(66 \%)$ were 30 years or less of age and $8(34 \%)$ were more than 30 years of age. The upper eyelid was reported to be affected in $77.5 \%$ of cases. The incidence was seen to be more in females $(68 \%)$.

This study has its strengths and weaknesses. The main strength of this study is the huge sample size. Other strengths included the format of data entry and retrieval which was EMR-based. The indigenously created and customized EMR allowed for a standardized data entry and data collection free of any transcription errors. ${ }^{9-11}$ The study included multiple centers of our eye care network across a wide geographic reach. This sort of a multitier network analysis allowed for the inclusion of both rural and urban populations, thus covering all the different demographic groups in the study.

The main limitation of this study is that it was not population-based but rather a hospital-based study. It has been shown however that hospital-based or medical recordsbased estimation of incidence/prevalence rates is a valid methodology and has been used in many studies previously 
to report prevalence rates. ${ }^{12,13}$ Population-based studies of this magnitude would be impractical since many patients of chalazion who have asymptomatic disease would be unlikely to seek medical care. In that sense this study would have possibly underestimated the overall population prevalence of chalazion. Another limitation is the follow up after treatment as most patients in our dataset were lost to follow up once treatment was initiated.

\section{Conclusion}

In conclusion, this large EMR-based big data driven study indicates that the prevalence of chalazion in an eye institute-based population is very low. The presenting population is young with a gender equivalence and largely comes from the middle class of society. Most patients are treated with conservative treatment. The occurrence of an inadvertent malignant lesion masquerading as a chalazion is extremely low.

\section{Acknowledgment}

The authors wish to acknowledge the support of our Department of eyeSmart EMR \& AEye team specially Mr Ranganath Vadapalli and Mr Mohammad Pasha.

\section{Disclosure}

The authors report no conflicts of interest in this work.

\section{References}

1. Al-Faky YH. Epidemiology of benign eyelid lesions in patients presenting to a teaching hospital. Saudi J Ophthalmol. 2012;26:211-216. doi:10.1016/j.sjopt.2011.05.005
2. Rumelt S, Rubin PA. Potential sources for orbital cellulitis. Int Ophthalmol Clin. 1996;36(3):207-222. doi:10.1097/00004397199603630-00019

3. Donaldson MJ, Gole GA. Amblyopia due to inflamed chalazion in a 13-month old infant. Clin Exp Ophthalmol. 2005;33:332-333. doi:10.1111/j.1442-9071.2005.00982.x

4. Chalazion A. Benign eyelid tumour- the Sagamu experience. Nijer J Ophthalmol. 2008;16:33-35.

5. Das AV, Kammari P, Vadapalli R, Basu S. Big data and the eyeSmart electronic medical record system - an 8-year experience from a three-tier eye care network in India. Indian J Ophthalmol. 2020;68:427-432. doi:10.4103/ijo.IJO_710_19

6. Ministry of Statistics and Program Implementation, Government of India [Internet]. c2020 [cited 2020 Mar 10]. Available from: http:// www.mospi.nic.in/sites/default/files/publication_reports/concepts_ golden.pdf.

7. Ministry of Human Resource Development, Government of India [Internet]. c2020 [cited 2020 Mar 10]. Available from: https://mhrd. gov.in/sites/upload_files/mhrd/files/upload_document/74amend.pdf. Accessed June 30, 2020.

8. Kumar J, Pathak AK, Verma A, Dwivedi S. Study of incidence and risk factors of chalazion in Bundelkhand region. IOSR J Dent Med Sci. 2017;16:5-8. doi:10.9790/0853-1605080508

9. Donthineni PR, Kammari P, Shanbhag SS, Singh V, Das AV, Basu S. Incidence, demographics, types and risk factors of dry eye disease in India: electronic medical records driven big data analytics report I. Ocul Surf. 2019;17:250-256. doi:10.1016/j.jtos.2019.02.007

10. Das AV, Donthineni PR, Sai Prashanthi G, Basu S. Allergic eye disease in children and adolescents seeking eye care in India: electronic medical records driven big data analytics report II. Ocul Surf. 2019;17:683-689. doi:10.1016/j.jtos.2019.08.011

11. Das AV, Podila S, Prashanthi GS, Basu S. Clinical profile of pterygium in patients seeking eye care in India: electronic medical records-driven big data analytics report III. Int Ophthalmol. 2020;40(6):1553-1563. doi:10.1007/s10792-020-01326-3

12. Lin D, Chen J, Lin Z, et al. 10-year overview of the hospital-based prevalence and treatment of congenital cataracts: the $\mathrm{CCPMOH}$ experience. PLoS One. 2015;10(11):e0142298. doi:10.1371/journal. pone. 0142298

13. Zhang G, Chen H, Chen W, Zhang M. Prevalence and risk factors for diabetic retinopathy in China: a multi-hospital-based cross-sectional study. Br J Ophthalmol. 2017;101(12):1591-1595. doi:10.1136/ bjophthalmol-2017-310316
Clinical Ophthalmology

\section{Publish your work in this journal}

Clinical Ophthalmology is an international, peer-reviewed journal covering all subspecialties within ophthalmology. Key topics include: Optometry; Visual science; Pharmacology and drug therapy in eye diseases; Basic Sciences; Primary and Secondary eye care; Patient Safety and Quality of Care Improvements. This journal is indexed on PubMed

\section{Dovepress}

Central and CAS, and is the official journal of The Society of Clinical Ophthalmology (SCO). The manuscript management system is completely online and includes a very quick and fair peer-review system, which is all easy to use. Visit http://www.dovepress.com/ testimonials.php to read real quotes from published authors. 